\title{
X-ışını Kırınımı (XRD) ve Taramalı Elektron Mikroskobu (SEM) Kullanılarak Kaynaklanan Göknar, Meşe ve Kestane Odununun Yapısal Karakterizasyonu
}

\author{
Mustafa ZOR ${ }^{1, *}$, Hızır Volkan GÖRGÜN², Mojgan VAZİR $\dot{I}^{3}$ \\ ${ }^{1}$ Zonguldak Bülent Ecevit Üniversitesi, Çaycuma MYO, Tasarım Bölümü, Zonguldak/TURKEY \\ ${ }^{2} 2$ İstanbul Üniversitesi-Cerrahpaşa, Orman Fakültesi, Orman Endüstri Mühendisliği Bölümü, İstanbul/TURKEY \\ ${ }^{3}$ Luleå University of Technology, Wood Science and Engineering, Skellefteå, Luleå/ SWEDEN
}

\section{Öz}

Bu çalışmada, kaynaklanmış göknar, meşe ve kestane odunlarının morfolojik analizlerini tanımlamak için taramalı elektron mikroskopu (SEM) ve selüloz kristanilitesini (CRI) tahmin etmek için X-1şını kırınım analizi (XRD) kullanılarak örnekler karakterize edilmiştir. Sonuçlar, XRD analizinde CRI değerlerinin göknar, meşe ve kestane ağacı örneklerinde sırasıyla \%57.55 ve \%47.73 ve \%56.66 olarak tespit edilmiştir. Diğer bir deyişle tüm ahşap örneklerin CRI değerinin, kaynağa tabi tutulduktan sonra arttığını göstermektedir. Bu artışın meşede, daha düşük çıkmasının nedeni olarak, polisakkarit oranı farklılığından kaynaklandığı söylenebilir. SEM analizine göre ise ahşabın genel hücre yapısı kendini korurken, kaynaklı ara fazı oluşturmak için kullanılan yüksek sıcaklık ve basınçla kırılmalar meydana geldiği ve kaynaklama işlemi ile katılaşmış-erimiş hücreler arası malzemeden bir ara yüz tabakası oluşturduğu gözlemlenmiştir. Malzemede oluşan bu yeni hücresel yapı nedeniyle, numunelerin açık kaynaklı kısımlarında mikroskobik ve makroskopik ölçekte yüzey pürüzlülüğünü ortaya çıkardığı gözlemlenmiştir.

Anahtar Kelimeler: Yüzey karakterizasyonu, sürtünme ahşap kaynak, taramalı elektron mikroskop, X-1şını kırınımı

\section{Structural Characterization of Welded Fir, Oak, and Chestnut using X-Ray Diffraction (XRD) and Scanning Electron Microscopy (SEM) Analysis}

\begin{abstract}
This work characterizes welded wood specimens by estimating the crystallinity of cellulose by x-ray diffraction (XRD) and scanning electron microscopy (SEM) to identify the morphology of the welded fir, oak, and chestnut woods. The results showed that the cellulose crystallinity index (CRI) in the XRD analysis were identified to be $57.55 \%$, 47.73\%, and 56.66\% for the fir, oak, and chestnut wood specimens, respectively. In other words, it shows that the CRI value of all wood samples increased after welding. It can be said that the reason lower increment in oak was due to the difference in polysaccharide ratio. According to the SEM analysis, it was observed that while the general cell structure of the wood was preserved, fractures occurred with the high temperature and pressure used to form the welded interphase. Additionally, an interface layer was formed from the solidified-molten intercellular material by the welding process. It has been observed that the open source parts of the samples reveal surface roughness at microscopic and macroscopic scales, due to this new cellular structure formed in the material.
\end{abstract}

Keywords: Surface characterization, friction wood welding, SEM, XRD 


\section{Giriş}

Bu makalenin amacı, ahşap materyallerin morfolojik bağlanma özelliklerini gözlemlemek ve tutkalsız bağlama teknolojisi olarak bilinen ahşap kaynak metodu ile birleştirilen masif ahşap numunelerinin kristalinite derecesini ölçmektir. Kaynak teknolojisi, yapıştırıcı içermeyecek şekilde ahşapta bağlantılar oluşturma alanındaki en son araştırma teorisi olarak bilinmektedir. Son yıllarda ahşap kaynağı, ahşap yapıştırmaya hızlı ve uygun maliyetli bir alternatif olduğu için metal, otomasyon ve diğer endüstrilerde tercih edilen bir yöntem haline gelmiştir (Martins vd., 2013; Zhang vd., 2014). Kaynak teknolojisi, mühendislik uygulamalarının pek çok alanında (metal ve plastik bağlantı endüstrisi vb.) yaygın olarak kullanılmaktadır. Ahşap kaynaklama işlemi ve bu işlem sonrası malzeme bağlantıların mekanik özellikleri son on yılda Avrupa'da incelenmiș ve bu kaynaklama yöntemi mobilya endüstrisinde (Stamm 2005; Navi ve Sandberg, 2012) ve yap1 kerestelerinin birleştirilmesinde (inşaat sektörü için) başarıyla uygulandığg söylenebilir (Pizzi vd., 2004).

Kaynaklama işleminde, ahşap malzemelerin birbirleriyle sürtünmesi nedeniyle karşılıklı bir ara yüz tabakası oluşarak arasında bağlanma meydana getirmekte ve ahşaptaki üç ana polimer olan selüloz, hemiselüloz ve ligninde bazı değişiklikler meydana getirmektedir. Bu işlem sırasında, bazı ahşap bileşenler sonunda katılaşıp sertleşmeden önce yumuşamaktadır. Ahşap ısıtıldığında, selüloz nispeten sabit olup, hemiselüloz üretimi termal pirolize uğramakta ve odun kaynağı işlemi sırasında depolimerize olan lignin yumuşayarak polimerleşmektedir (Vaziri 2011; Sandberg vd., 2013: Zhou vd., 2014). Ahşabı birbirine bağlamak için sürtünme kuvvetindeki meydana gelen 1s1, hücresel bozulma tarafından üretilen 1sı olarak görülmektedir (Gfeller ve diğerleri, 2003). Yapılan bir çalışmada, ahşap yüzeylerin titreşim kaynağı ile yapışmasına, bağlanan ara yüzdeki ahşap yoğunluğunda önemli bir artış olduğu görülmektedir (Gfeller vd., 2003; Leban vd., 2004). Kristalinite derecesi, düzenli (kristal) ve düzensiz (amorf) selülozun oranı ve konfigürasyonu olması nedeniyle ahşap özelliklerini değerlendirmek için çok kullanışlıdır. Selüloz kristalliğinin belirlenmesi, ağaç işleme alanlarında ahşap bileşenlerin doğru kullanımı için oldukça önemli olduğu bilinmektedir. Bu kapsamda, X-ışını kırınımı (XRD) ve taramalı elektron mikroskobik (SEM) analizi, bazı araştırmacılar tarafından, kaynak sonrası ahşap yüzeylerin iç yapışma mukavemetini incelemek ve bağlantıların selüloz kristallik değerlerini ortaya çıkarmak için kullanılmıştır (Pizzi vd., 2004; Properzi vd., 2005). Ahşap bileşenler değiştikçe, serbest fenolik hidroksil gruplarının sayısı artmakta ve ara yüzeyin stabilitesini güçlendirmek için selüloz ile hidrojen bağları oluşmaktadır (Delmotte vd. 2009). Zhu vd. (2017) yaptığı bir çalışmada, ahşap dübeller ile ahşap malzeme arasındaki etkileşimi incelemiş ve ahşap dübel kaynak işleminden sonra XRD kullanılarak selülozun kristallik derecesinin arttırdığını ifade etmişlerdir.

Literatürde kaynak teknolojisinde kullanılan bazı ağaç türleri mekanik testlere (makaslama/kesme dayanımı) ve fiziksel testlere (su absorpsiyonu, çatlak analizleri ve X-1şını mikro densitometresi) tabi tutulmuştur. Çam odunu (Vaziri vd. 2009; Vaziri vd., 2010), kayın odunu (Stamm vd., 2005), ladin odunu (Gfeller vd., 2003; Jones ve Pizzi 2009), kavak odunu (Ganne-Chedeville vd., 2006), iroko, dişbudak, lale ve ayous odunları (Zor, 2020) gibi kaynak teknolojisinde kullanılmak üzere farklı ağaç türlerinin karakterizasyon analizlerine rastlanmaktadır. Mobilya endüstrisinde özellikle dış mekânlarda yaygın olarak kullanılan göknar, meşe ve kestane türlerinin, kaynaklanma işlemi sonucu oluşan değişimlerle ilgili XRD ve SEM analizleri incelemelerin literatürde henüz yer almadığı söylenebilir. Bu çalışmada, Delmotte vd. (2008) ile Segovia ve Pizzi’nin (2009) yaptığı çalışmalardaki yöntem kullanılarak, bahsi geçen ağaç türlerin kaynaklanma işlemi sonucu XRD metodu ile selüloz kristallik derecesini belirlenmesi ve SEM metodu kullanarak morfolojik değişiklikleri gözlemlenmesi amaçlanmıştır.

\section{Materyal ve Metot}

\subsection{Materyal}

Göknar (Abies bornmulleriana Mattf.), meşe (Quercus robur L.) ve kestane (Castanea sativa Mill.) odunları, Türkiye'de faaliyet gösteren bir fabrikadan temin edilmiş ve $200 \mathrm{~mm} \times 20 \mathrm{~mm} \times 20 \mathrm{~mm}$ boyutlarındaki numunelere ebatlanmıştır. Test edilmeden önce numuneler \% 12 rutubet içeriğine ulaşana kadar (\%65 bağıl nem ve $20^{\circ} \mathrm{C}$ sicaklık) iklimlendirme odasında bekletilmiştir. Numuneler, Luleå Teknoloji Üniversitesi, İsveç'te doğrusal bir titreşimli kaynak makinesi ile (LVW 2061; Mecasonic, Annemasse, Fransa), nihai boyutları $200 \mathrm{~mm}$ $\times 20 \mathrm{~mm} \times 40 \mathrm{~mm}$ (Boy x Radyal x Teğet) olacak şekilde birbirlerine bağlantı oluşturmak için her seferinde iki parça birbirine kaynaklanma işlemine tabi tutulmuştur. İşlem Tablo 1'deki kaynak makinesi parametrelerine göre gerçekleştirilmiştir. Testler sonrasında malzemeler üzerinde daha detaylı araştırmalar elde etmek için Zonguldak Bülent Ecevit Üniversitesi'nde XRD ve SEM analizlerine dayalı karakterizasyonu belirlemek için ilgili ölçümlere uygun olacak şekilde numuneler hazırlanmıştır. 
Tablo 1. Örneklerin hazırlanmasında kullanılan makine parametreleri.

\begin{tabular}{ccc}
\hline Parametre & Birim & Değer \\
\hline Kaynaklama Basıncı (WP1 and WP2) & $\mathrm{MPa}$ & $1.3-1.8$ \\
\hline Kaynaklama Süresi (WT1 and WT2) & $\mathrm{s}$ & $2.5-3.0$ \\
\hline Kaynak Hareketi (WD) & $\mathrm{mm}$ & 2.0 \\
\hline Siklık & $\mathrm{Hz}$ & 150.0 \\
\hline Tutma-Kaldırma Basıncı (HP) & $\mathrm{MPa}$ & 2.0 \\
\hline Kaldırma Süresi (HT) & $\mathrm{s}$ & 10.0
\end{tabular}

\subsection{Metot}

\subsubsection{X-ışını kırınımı (XRD)}

X-ışını kırınımı (XRD) ölçümleri, bir PANalytical XRD difraktometresi (Hollanda) üzerinde oda sıcaklığında gerçekleştirilmiştir. Tüm örneklerin kristalin yapısal analizi, CuKa radyasyonlu $(\lambda=1.5406 \AA)$ bir difraktometre üzerinde kaydedilmiştir. $\mathrm{X}$-1şını difraktometresi, $40 \mathrm{~mA}$ akım yoğunluğu ile $40 \mathrm{kV}$ voltajda çalıştırılmıştır. Tarama aralı̆ $\mathrm{g} 10,071^{\circ}$ s tarama hızında $2 \theta=10^{\circ}$ ila $90^{\circ}$ arasındadır. Kristallik indeksi (CrI), kristalinite değerinin belirlenmesi için Segal vd., (1959) tarafindan kullanılan pik yüksekliği (Peak height) ve Curve Fitting metodundan yararlanılmıştır.

\subsubsection{Taramalı Elektron Mikroskobu (SEM)}

Numunelerin morfolojik özellikleri, $15 \mathrm{kV}$ hızlanma voltajında bir Quanta 450 FEG masa üstü mikroskobu (FEI Company, Hillsboro, OR) kullanılarak karakterize edilmiştir. Test numuneleri sıvı nitrojene daldırılmış ve malzemeler uygun bir kesici yardımı ile pürüzsüz olacak şekilde ikiye bölünerek, test numuneleri kaynak bölgesinden alınmıştır.

\section{Bulgular ve Tartışma}

\section{X-ışını kırınımı (XRD)}

X ışını kırınımı, özellikle lignoselülozik malzemeler arasında yer alan ahşap, farklı molekül içi ve moleküller arası hidrojen bağlarında yer alan ve kristal düzenlemelere sahip olan selüloz makro moleküllerinde serbest hidroksil gruplarının varlığından dolayı belirli bir derecede selüloz kristalinitesi sergilemektedir (Broda ve Carmen-Mihaela, 2019). Tablo 1'de, bu çalışma kapsamında elde edilen X-ışını kırınım sonuçları ile selüloz kristanilite değerleri verilmiştir. X-ışını kırınımı, kaynaklanan odun tiplerine göre göknar ve kestanede birbirine yakın olduğu görülmektedir. Kaynaklanmamış kontrol numuneleri ile karşılaştırıldığında, kaynak işlemi ağaç türlerinin selüloz kristalinite değerinde artışlar meydana getirdiği tespit edilmiştir. Bu sonuçların farklı orandaki lignin ve polisakkarit içeriği ile ilişkili olduğunu gösteren literatür ile uyumlu olduğu söylenebilir (Betts vd., 1997; Malherbe ve Cloete, 2002; Mathews vd., 2015).

Tablo 1. Kaynaklanmış ve kaynaklanmamış odun örneklerinin ortalama selüloz kristanilite indeksleri

\begin{tabular}{ccc}
\hline Örnek & $\mathbf{2 \theta}$ & Cr.I (\%) \\
\hline Kaynaklanmış Göknar & 22,54 & 57,55 \\
\hline Kaynaklanmamış Göknar & 22,3 & 32 \\
\hline Kaynaklanmış Meşe & 22,57 & 47,73 \\
\hline Kaynaklanmamış Meşe & 22,3 & 46,2 \\
\hline Kaynaklanmış Kestane & 22,51 & 56,68 \\
\hline Kaynaklanmamış Kestane & 22,3 & 36 \\
\hline
\end{tabular}




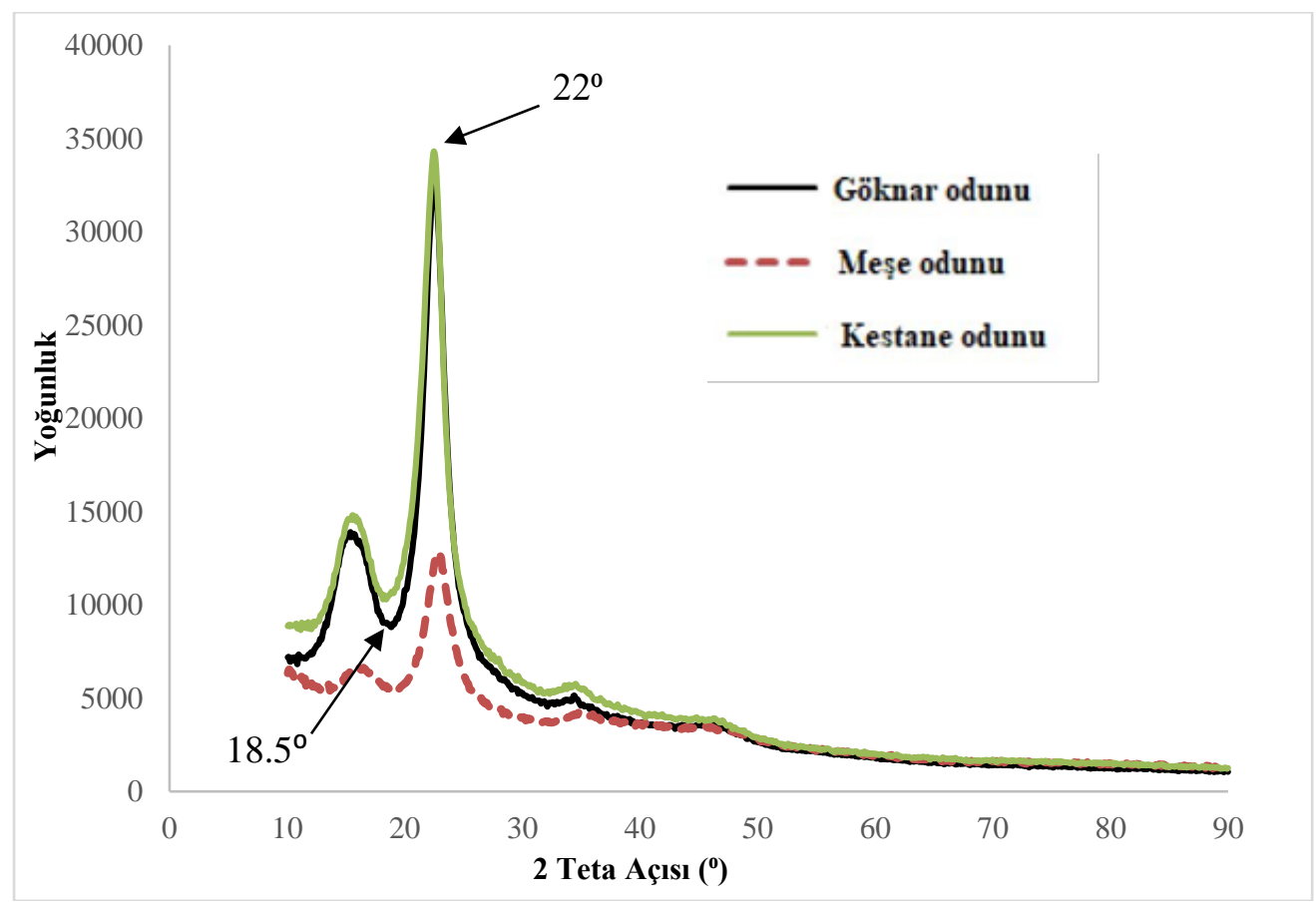

Şekil 1. Kaynaklanmış ve kaynaklanmamış odun örneklerinin XRD sonucu

Ahşap, yüksek 1sıdan dolayı hidrolize uğramakta ve yapısal olarak değişen bu malzemenin selüloz kristanilite derecesinin belirlenmesinde önemli bir rol oynamaktadır. Kaynak işlemi sırasında, odun bileşenlerinde selüloz, hemiselüloz ve ligninin depolimerizasyonu ve pirolizi dâhil kimyasal değişiklikler meydana gelmektedir (Sun ve diğerleri 2010; Manhert ve diğerleri 2013). Zhu vd. (2017), hemiselüloz ve ligninin bazı kısımlarının hidrolizinden kaynaklanan selüloz kristallik derecesini arttıran mono kristaller oluşturduğunu belirtmişlerdir.

\section{Taramalı Elektron Mikroskobu (SEM)}

Şekil 2, 3 ve 4, kaynaklanmış ahşap örneklerinin yüzey morfolojilerini göstermektedir. 500× ve 5000× büyütmede kaynak sırasında elde edilen selüloz lifleri ve ağaç hücreleri (traheid) ile lignin füzyonunun SEM görüntüleri, karışık ve ayrılmış traheidleri, kaynaşmış bir hücreler arası lignin kütlesini ve erimiş bir lignine daldırılmış traheidleri ve lifleri göstermektedir. Kaynak işlemi sırasında ağaç lifleri yırtılarak tahrip edilmektedir. Bu nedenle ahşap, orijinal hücresel yapısını kaybetmektedir. Kaynaklı ahşap, ısının etkisiyle daha düşük geçirgenliğe neden olarak kristanilite yoğunluğunu arttırmıştır.
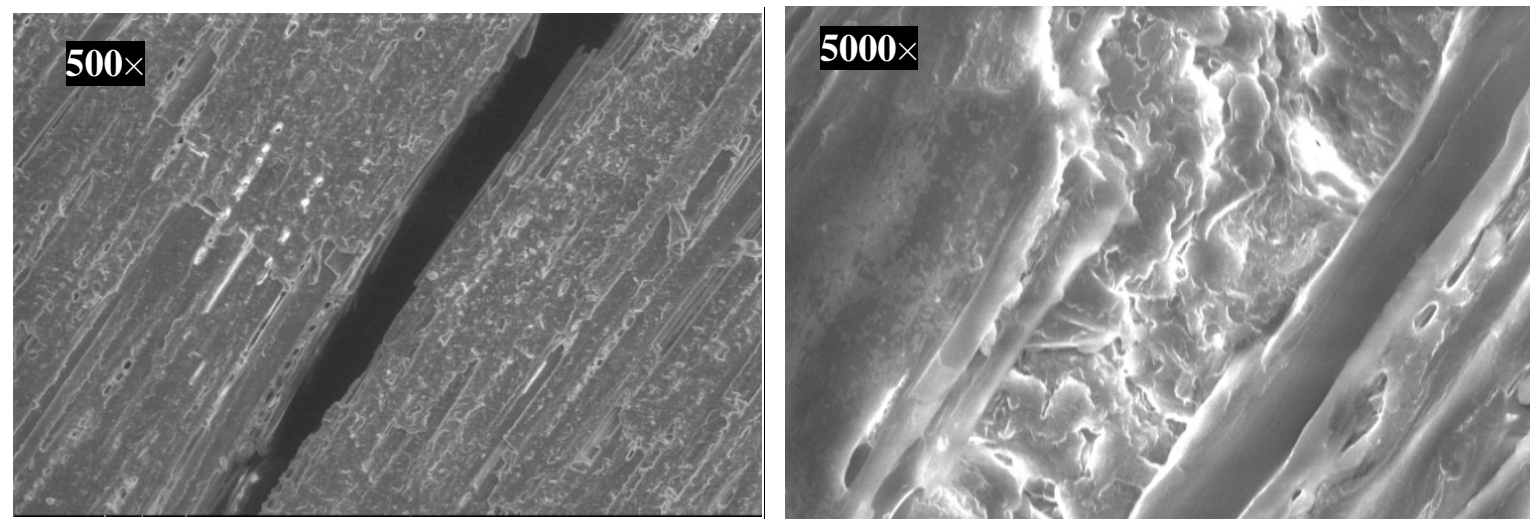

Şekil. 2. Kaynaklanmış göknar odunu ve açık kaynak bölgesinin SEM görüntüsü 

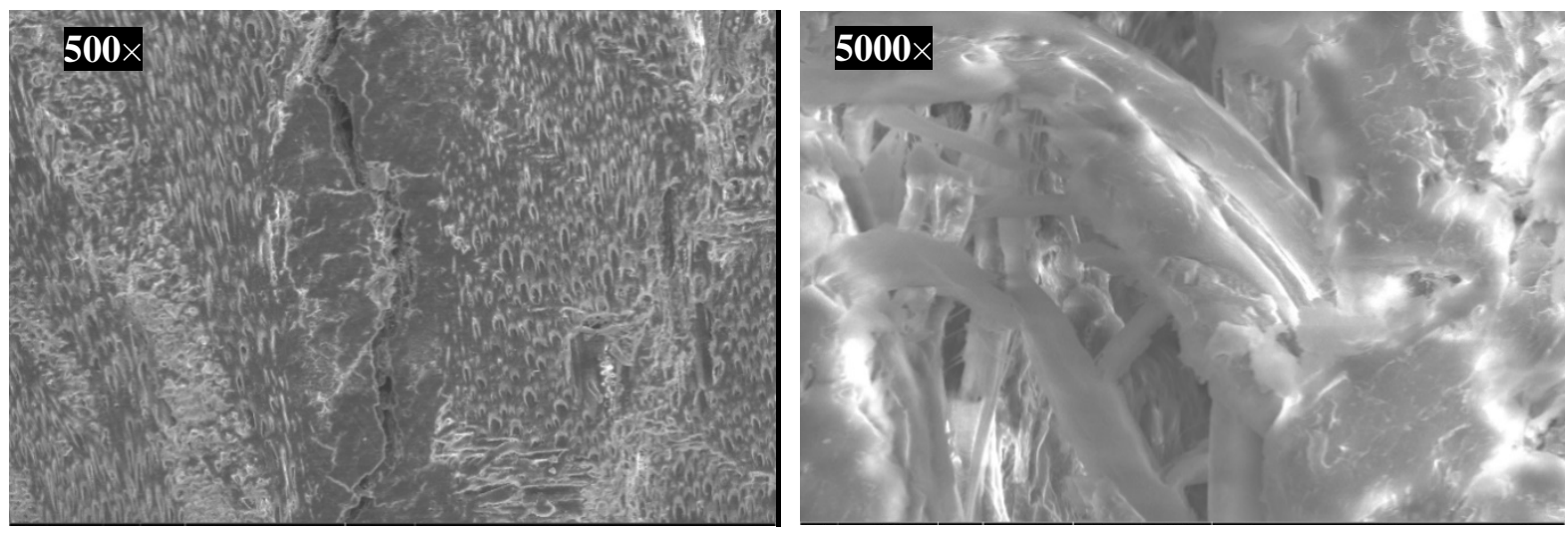

Şekil. 3. Kaynaklanmış meşe odunu ve erimiş ligninin SEM görüntüsü
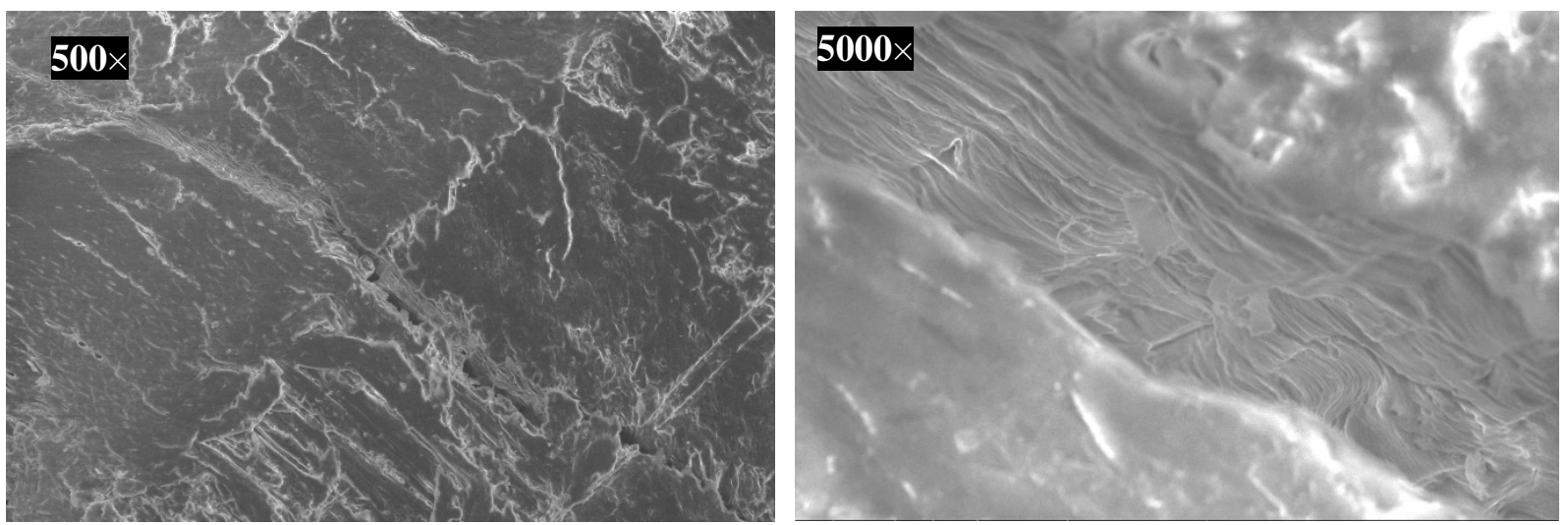

Şekil. 4. Kaynaklanmış kestane odunu ve ara yüzey tabakasının SEM görüntüsü

Kaynaklama işlemi ile katılaşmış-erimiş hücreler arası malzemeden bir ara yüz tabakası oluşturduğu tespit edilmiştir. Bunun malzemede hücresel bir yapı oluşturduğu ve numunelerin açık kaynaklı kısımlarında mikroskobik ve makroskopik ölçekte yüzey pürüzlülüğünü ortaya çıkardığı görüldüğü söylenebilir. Benzer sonuçlar, Vaziri vd. (2020) tarafından yapılan çalışmada da görülmektedir.

\section{Sonuç ve Öneriler}

1. Kaynaklanmış ağaç örnekleri için kristalinite derecesi sırasıyla göknar, meşe ve kestane ağaç türleri için \% 57.55, \% 47.73 ve \% 56.66 olarak bulunmuştur. Kaynaklama işleminden sonra kısmen parçalanmış yüzeylerin yeniden kristalleşmesi ve düzenlenmesi nedeniyle selüloz kristalinite derecesini arttırmıştır. XRD analizi, selüloz ve hemiselüloz pirolizinin kaynak işlemi sırasında gerçekleştiğini ortaya koymaktadır.

2. SEM analizi ile kaynaklı malzemelerin ara yüzeyleri hidrofobik kimyasal yapıya sahip daha yoğun yapı oluştuğunu göstermiş ve kırılmaların yüzeylerde yüksek 1sı ile meydana geldiği gözlemlenmiştir.

3. Kaynak birleştirme teknolojisi orman ürünleri endüstrisinde oldukça yeni bir alandır. Kaynak süresi, rutubet ve suya daldırma gibi birçok ahşap kaynağı parametresi daha önce çalışılmıştır. Farklı ağaç türleri üzerinde, bu parametreler daha fazla değerlendirilmeli ve kullanım alanlarına göre yapısal ileri analiz metodları ile desteklenmelidir. Malzemelerin mekanik özellikleriyle birlikte, selüloz kristalinite değerlerinin belirlenmesi ve morfolojik testlerle gözlemlenmesi de orman ürünleri sektöründe, ahşap malzemenin kullanım ömrü açısından bilgi edinmede destekleyici uygulamalardan olduğu söylenebilir.

\section{Teşekkür}

Yazarlar, ahşap malzemelerin temininde destek sağladığı için Nova Orman Ürünlerine teşekkür etmektedir. Ayrıca yazarlar, konuk araştırmacı Dr. Mustafa ZOR'a, İsveç, Skellefteå'daki Luleå Teknoloji Üniversitesi'nde yapması için burs desteği aldığı Türkiye Bilimsel ve Teknolojik Araştırma Kurumu'na (TÜBİTAK- 2219/BIDEB, 2019) teşekkür eder. 


\section{Kaynaklar}

1. Betts R.A., Cox, P.M., Lee, S.E., Woodward, F.L. (1997). Contrasting physiological and structural vegetation feedbacks in climate change simulations. Nature 387: 796-799.

2. Broda M., Carmen-Mihaela P., (2019). Natural decay of archaeological oak wood versus artificial degradation processes-An FT-IR spectroscopy and X-ray diffraction study. Spectrochimica Acta Part A: Molecular and BiomolecularSpectroscopy 209;280-287.

3. Ganne-Chedeville, C., Properzi, M., Pizzi, A., Leban, J-M. and Pichelin, F. (2006). Parameters of wood welding: a study with infrared thermography, Vol. 60, 2006, pp. 434-438.

4. Jones, D. and Pizzi, A. (2009). Frictional Welding of Dowels into Modified Wood. Cost Action E34 Workshop in Slovenia on Bonding of Modified Wood.

5. Delmotte, L., Mansouri, H.R., Omeani, P., Pizzi, A. (2009). “Influence of wood welding frequency on wood constituents chemical modifications. J Adhes Sci Technol 23:1271-1279.

6. Ganne-Chedeville, C., Pizzi, A., Thomas, A., Leban, J.M., Bocquet, J.F., Despres, A., Mansouri, H. (2005). Parameter interactions in twoblock welding and the wood nail concept in wood dowel welding. J Adhes Sci Technol 19:1157-1174.

7. Gfeller, B., Zanetti, M., Properzi, M., Pizzi, A., Pichelin F., Lehmann, M., and Delmotte L. (2003). Wood bonding by vibration welding. J. Adhes. Sci. Technol. 17, 1425-1590. DOI: 10.1163/156856103769207419.

8. Karl-Christian, M., Stergios, A., Gerald, K., Holger, M. (2013). Topochemistry of heat-treated and Nmethylol melamine-modified wood of koto (Pterygota macrocarpa K. Schum.) and limba (Terminalia superba Engl. et Diels). Holzforschung 67:137-146.

9. Delmotte, L., Ganne-Chedeville, C., Leban, J-M., Pizzi, A. and Pichelin, F. (2008). CPMAS ${ }^{13}$ C NMR and FT-IR investigation of the degradation reactions of polymer constituents in wood welding, Polymer Degrad. \& Stabil. 93, 406-412

10. Leban, J.-M., Pizzi, A., Wieland, S., Zanetti, M., Properzi, M. and Pichelin, F. (2004). X-ray microdensitometry analysis of vibration-welded wood. Journal of Adhesion Science and Technology, 18, 673685.

11. Properzi, M., Leban, J-M., Pizzi, A., Wieland, S., Pichelin, F. and Lehmann, M. (2005). Influence of grain direction in vibrational wood welding, Holzforschung. 59, 23-27

12. Malherbe, S., Cloete, T.E. (2002). Lignocellulose biodegradation: fundamentals and applications. Reviews in Environmental Science and Biotechnology 1: 105-114.

13. Martins, S.A., Ganier, T., Pizzi, A., and Del Menezzi, C. H. S. (2013). Parameter scanning for linear welding of Brezilian Eucalyptus benthamii wood. Eur. J. Wood. Prod., 71, 525-527. DOI:10.1007/s00107-013-0696-1.

14. Mathews, S.L., Pawlak, J., Grunden, A.M. (2015). Bacterial biodegradation and bioconversion of industrial lignocellulosic streams. Applied Microbiology and Biotechnology 99: 2939-2954.

15. Navi, P., and Sandberg, D. (2012). Thermo-Hydro-Mechanical Processing of Wood. EPFL Press, Lausanne, Switzerland, pp. 47-50.

16. Pizzi, A., Leban, J.-M., Kanazawa, F., Properzi, M. and Pichelin, F. (2004). Wood dowel bonding by highspeed rotation welding. Journal of Adhesion Science and Technology, 18, 1263-1278.

17. Sandberg, D., Haller, P., Navi, P. (2013). Thermo-hydro and thermos-hydro-mechanical wood processing: an opportunity for future environmentally friendly wood products. Wood Mater Sci Eng 8 (1):64-88.

18. Segal, L., Creely, J.J, Martin, Jr, A.E, Conrad, C.M. (1959). An empirical method for estimating the degree of crystallinity of native cellulose using the x-ray diffractometer. Textile Research Journal 29: 786-794.

19. Segovia, C., Pizzi, A. (2009). Performance of dowel-welded wood furniture linear joints. J Adhes Sci Technol 23:1293-1301

20. Stamm, B. (2005). Development of friction welding of wood physical, mechanical and chemical studies. PhD thesis No. 3396, Ecole Fe'de'rale de Lausanne, Switzerland.

21. Sun, Y., Royer, M., Diouf, P.N., Stevanovic, T. (2010). Chemical changes induced by high-speed rotation welding of wood-application to two Canadian hardwood species. J Adhes Sci Technol 24:1383-1400.

22. Vaziri, M., Lindgren O., and Pizzi, A. (2009). Influence of welding parameters and wood properties on water absorption in Scots pine joints induced by linear friction welding. J. Adhes. Sci. Technol. 25(15), 1819-1828. DOI: $10.1163 / 016942410 X 525731$

23. Vaziri, M., Lindgren, O., Pizzi, A., and Mansouri, H. R. (2010). Moisture sensitivity of Scots pine joints produced by linear frictional welding. J. Adhes. Sci. Technol. 24(8), 1515-1527. DOI: 10.1163/016942410X501098.

24. Vaziri, M., Karlsson, O., Abrahamsson L., Lin C-F, and Sandberg, D. (2020). Wettability of welded woodjoints investigated by the Wilhelmy method. Part 1: Determination of Apparent Contact Angles, Swelling and Water Sorption. Holzforschung. Doi.org/10.1515/hf-2019-0308.

25. Zhang, H., Pizzi, A. and Xiaoning, L. (2014).Palmyra palm bonding by vibrational welding. Eur. J. Wood Prod., 72, 693-695. DOI: 10.1007/s00107-014-0825-5. 
26. Zhang, H., Pizzi, An., Lu, X. And Zhou, X., (2014). Optimization of Tensile Shear Strength of Linear Machanically Welded Outer-to-Inner Flattened Moso Bamboo (Phyllostachys pubescens). BioResources,9(2):2500-2508.

27. Zhou, X.J, Pizzi, A., Du, G.B. (2014). Research progress of wood welding technology (bonding without adhesive). China Adhesives 23: 47-53.

28. Zhu, X., Y, S., Gao, Y., Zhao, Y., Qiu, Y. (2017). Mechanical evaluation and XRD/TG investigation on the properties of wooden dowel welding. BioRes, 12(2):3396-3412.

29. Zor, M., Görgün, V. H., Mojgan V. (2019). Water Resistance of Welded Oak, Fir and Chestnut. III. International Mediterranean Forest and Environment Symposium, Kahramanmaraş, TURKEY.

30. Zor, M. (2020). Water resistance of heat-treated welded Iroko, Ash, Tulip and Ayous wood. BioRes, 15(4):9584-9595. 